Prepared for the U.S. Department of Energy

under Contract DE-AC05-76RL01830

\title{
Report on Second Activations with the Lead Slowing Down Spectrometer
}

SC Stave

EK Mace

SL Pratt

GA Warren

April 2012

\section{Pacific Northwest}

NATIONAL LABORATORY

Proudly Operated by Battelle Since 1965 


\title{
DISCLAIMER
}

This report was prepared as an account of work sponsored by an agency of the United States Government. Neither the United States Government nor any agency thereof, nor Battelle Memorial Institute, nor any of their employees, makes any warranty, express or implied, or assumes any legal liability or responsibility for the accuracy, completeness, or usefulness of any information, apparatus, product, or process disclosed, or represents that its use would not infringe privately owned rights. Reference herein to any specific commercial product, process, or service by trade name, trademark, manufacturer, or otherwise does not necessarily constitute or imply its endorsement, recommendation, or favoring by the United States Government or any agency thereof, or Battelle Memorial Institute. The views and opinions of authors expressed herein do not necessarily state or reflect those of the United States Government or any agency thereof.

\author{
PACIFIC NORTHWEST NATIONAL LABORATORY \\ operated by \\ BATTELLE \\ for the \\ UNITED STATES DEPARTMENT OF ENERGY \\ under Contract DE-AC05-76RL01830
}

Printed in the United States of America
Available to DOE and DOE contractors from the Office of Scientific and Technical Information,
P.O. Box 62, Oak Ridge, TN 37831-0062;
ph: (865) 576-8401
fax: $(865)$ 576-5728
email: reports@adonis.osti.gov

\begin{abstract}
Available to the public from the National Technical Information Service, U.S. Department of Commerce, 5285 Port Royal Rd., Springfield, VA 22161 ph: (800) 553-6847 fax: $(703) 605-6900$ email: orders@ntis.fedworld.gov online ordering: http://www.ntis.gov/ordering.htm
\end{abstract}

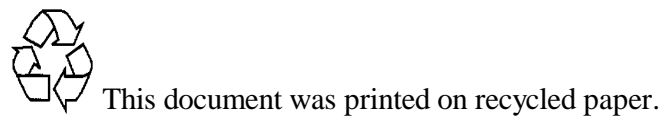




\section{Report on Second Activations with the Lead Slowing Down Spectrometer}

SC Stave

EK Mace

SL Pratt

GA Warren

April 2012

Prepared for

the U.S. Department of Energy

under Contract DE-AC05-76RL01830

Pacific Northwest National Laboratory

Richland, Washington 99352 


\section{Summary}

On August 18 and 19 2011, five items were irradiated with neutrons using the Lead Slowing Down Spectrometer (LSDS). After irradiation, dose measurements and gamma-spectrometry measurements were completed on all of the samples. No contamination was found on the samples, and all but one provided no dose. Gamma-spectroscopy measurements qualitatively agreed with expectations based on the materials. As during the first activation run, we observed activation in the room in general, mostly due to ${ }^{56} \mathrm{Mn}$ and ${ }^{24} \mathrm{Na}$. Most of the activation of the samples was short lived, with half-lives on the scale of hours to days, except for ${ }^{60} \mathrm{Co}$ which has a half-life of $5.3 \mathrm{y}$. 


\title{
Acronyms and Abbreviations
}

\author{
PNNL \\ Pacific Northwest National Laboratory \\ RPT \\ Radiation Protection Technician \\ HPGe \\ High-purity germanium \\ LSDS \\ Lead slowing down spectrometer/spectroscopy
}




\section{Contents}

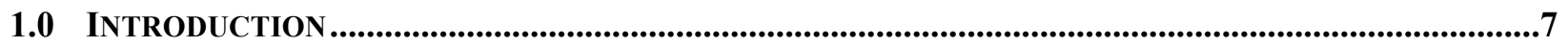

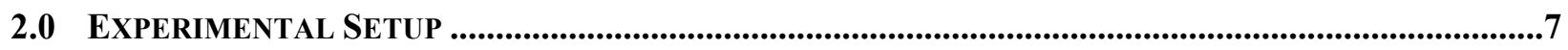

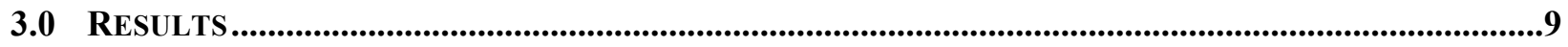

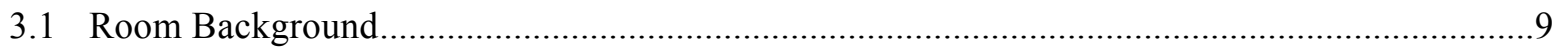

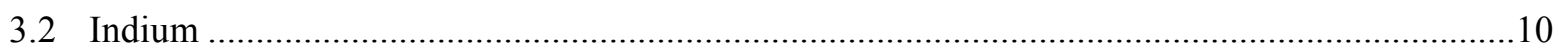

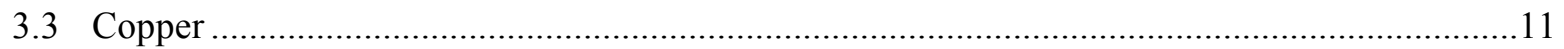

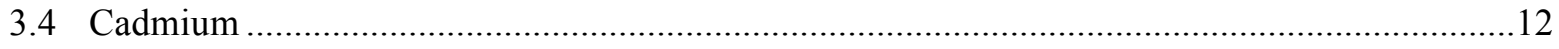

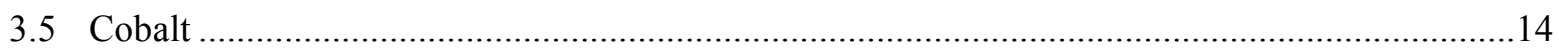

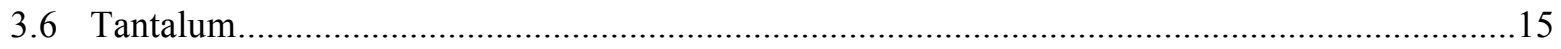

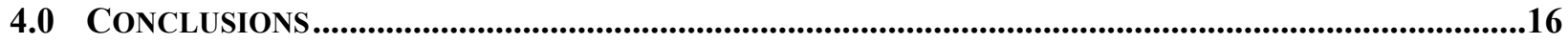

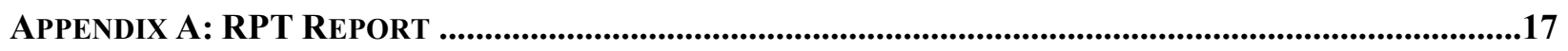




\section{Introduction}

The research activities related to the Lead Slowing Down Spectrometer (LSDS) are not typically done at PNNL. As such, the project management has taken a step-wise approach to build a strong safety basis for these activities. Using a series of measurements, the mid-term objective is to correlate the neutron energy with neutron slowing-down time as the neutrons progressively lose energy as they collide with the $\mathrm{Pb}$ nuclei in the LSDS. These measurements will be conducted by placing metal foils outside of a scintillator and measuring the time dependence of various $(n, \gamma)$ processes. However, before these measurements can begin, we need to understand the potential radiological safety concerns generated by placing a variety of materials in the neutron field of the LSDS.

As a first step, we irradiated six items in the LSDS in February 2011, and then conducted dose and gamma-spectroscopy measurements to develop a better understanding of the risks. The air release permit from the State of Washington did not allow the testing of additional foils until August, 2011. This report describes the activations and the ensuing characterization measurements of a second set of foils which completes the initial radiological safety tests.

\subsection{Experimental Setup}

The LSDS is a 1.5-m cube of lead that has been built to test concepts for use in direct measurements of Pu mass in spent fuel. A deuterium-tritium neutron generator is used to create $14-\mathrm{MeV}$ neutrons inside the lead cube. The generator can produce up to $3 \times 10^{8}$ neutrons per second. One millimeter of cadmium is placed on the outside of the lead stack to absorb thermal neutrons, both from within the lead and those that escaped outside of the lead and then scatter back inside ("room return"). The neutron generator was placed in the horizontal hole on the side of the stack, while the samples were put down the $41 / 8$ " diameter vertical hole that is $45^{\prime \prime}$ deep. A photo of the lead stack is shown in Figure 1.

The five irradiated items are summarized in Table 1, listed in order of decreasing expected activity. These items are foils of indium, copper, cadmium, cobalt, and tantalum. The metal foils were placed inside of nylon bags to reduce removable contamination risks. The samples were lowered down the vertical hole of the LSDS using fishing line. All of the samples were irradiated for an hour by a continuous source of D-T neutrons, with settings of $60 \mu \mathrm{A}$ and $90 \mathrm{kV}$ on the neutron generator. 

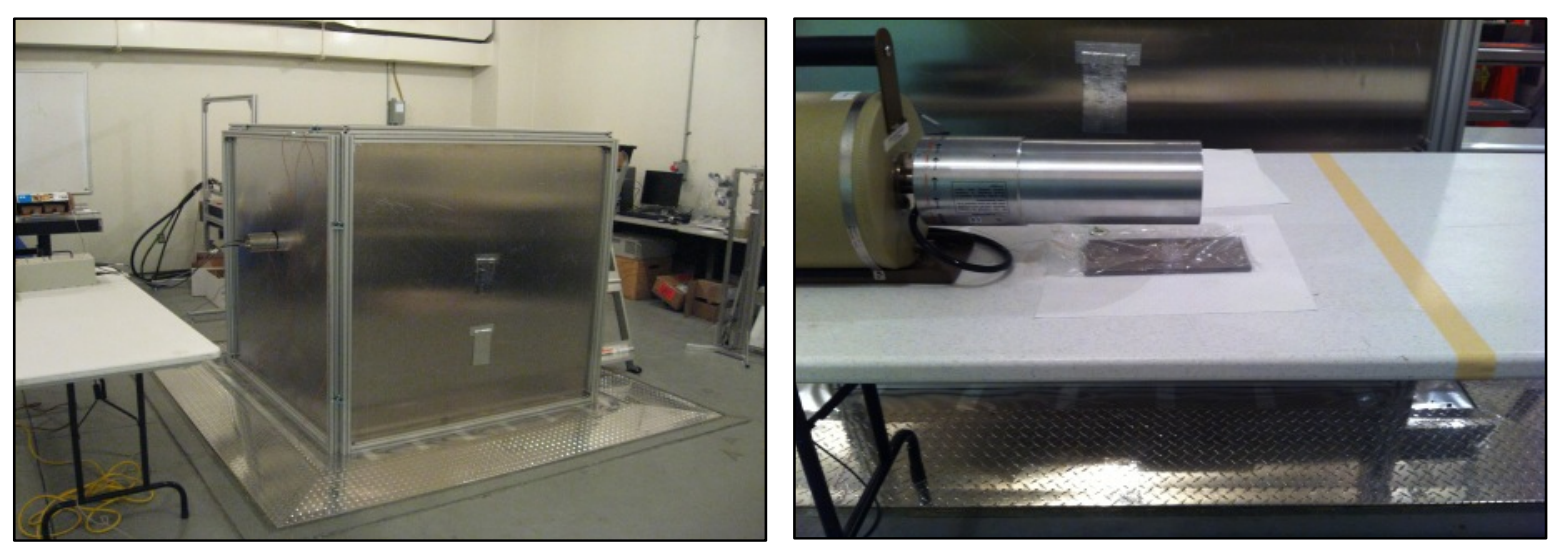

Figure 1: Photo of the lead stack with the DT generator in place (left) and photo of the HPGe detector measuring a foil in Feb., 2011(right). Note that the table was moved between photos.

Table 1: Summary of irradiated samples. Weight does not include the nylon bag. ${ }^{24} \mathrm{Na}$, with signatures at 1368.6 and $2754.0 \mathrm{keV}$ with a half-life of $14.7 \mathrm{~h}$, and ${ }^{56} \mathrm{Mn}$, with signatures at $846.8,1810.8$ and $2113.2 \mathrm{keV}$ with a half-life of $2.6 \mathrm{~h}$, appear in most of the spectra.

\begin{tabular}{|c|c|c|c|c|}
\hline Sample & $\begin{array}{c}\text { Weight } \\
(\mathbf{g})\end{array}$ & $\begin{array}{c}\text { Isotopes } \\
\text { Observed }\end{array}$ & $\mathbf{T}_{\mathbf{1 / 2}}$ & $\begin{array}{c}\boldsymbol{\gamma} \text { Signature } \\
(\mathbf{k e V})\end{array}$ \\
\hline Indium & 4.76 & In-116m & $54.2 \mathrm{~m}$ & $417,1097,1294$ \\
\hline Copper & 1107.2 & $\mathrm{Cu}-66$ & $5.1 \mathrm{~m}$ & 1039 \\
\hline Cadmium & 521.4 & $\begin{array}{c}\mathrm{Cd}-115 \\
\mathrm{Cd}-117\end{array}$ & $\begin{array}{c}53.5 \mathrm{~h} \\
2.49 \mathrm{~h}\end{array}$ & $\begin{array}{c}336,528 \\
273,34,1303,1576\end{array}$ \\
\hline Cobalt & 54.45 & $\mathrm{Co}-60$ & $5.3 \mathrm{y}$ & 1173,1332 \\
\hline Tantalum & 53.93 & Ta-182 & $114 \mathrm{~d}$ & $1121,1189,1221,1231$ \\
\hline
\end{tabular}

After irradiation, the samples were retrieved by a Radiation Protection Technician (RPT). The samples were swiped to test for removable contamination and also checked for gamma and beta dose and counts. No contamination was found, but the samples were activated. When it was initially pulled out of the stack, the indium had $2.0 \mathrm{mR} / \mathrm{h}$ dose rate at 1 inch for betas, but no dose for gammas. All of the foils except indium registered less dose than the detector limit of $0.5 \mathrm{mR} / \mathrm{h}$. The copper had a direct survey beta-gamma result of $5000 \mathrm{dpm} / 100 \mathrm{~cm}^{2}$. The RPT reports are provided in Appendix A.

A $120 \%$ relative efficiency HPGe detector was used to conduct the gamma spectroscopy measurements. The heavier copper and cadmium samples were placed on the table 4.375 " below the center of the detector, while the lighter indium, cobalt and tantalum were placed on top of the detector. The HPGe detector was removed from the vault while the neutron generator was running. The HPGe was tested prior to the measurements and the resolution was determined to be acceptable, having about a 2.2 
keV FWHM at the $1460 \mathrm{keV}^{40} \mathrm{~K}$ line. The data acquisition system had 16384 channels and a full range of about $3100 \mathrm{keV}$, yielding approximately $0.19 \mathrm{keV} /$ channel.

\subsection{Results}

\subsection{Room Background}

Once the neutrons are generated in the room, many materials in the room can become activated. As a check on this possibility, background runs were completed before the neutron generator was turned on and after it had been run for several hours. The spectrum in Figure 2 shows strong $\mathrm{Mn}^{56}$ lines, which likely result from either the activation of iron or manganese. Lines at 270, 336, 511, 528 and $806 \mathrm{keV}$ also appear in the spectrum but have not been identified. Manganese-56 has a half-life of $2.6 \mathrm{~h}$, so its activity will be negligible after roughly one day. this incidental activation of the room will disappear over the period of roughly a day.

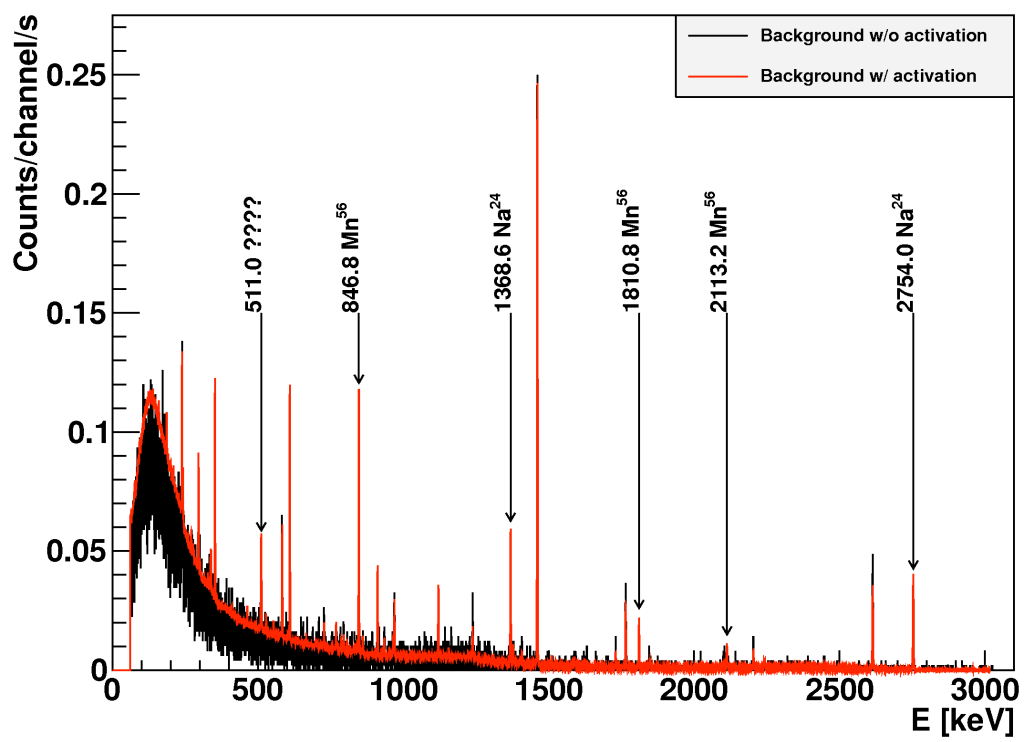

Figure 2: Comparison of room background before and after activation 


\subsection{Indium}

Indium was expected to have the highest activity post-irradiation amongst the second set of foils. A significant deviation from the background was observed, and it was most likely due to the many Compton edges from the gamma-rays and the beta spectrum from the beta-emitters. The indium foil was placed directly on the HPGe detector (while still in the nylon bag), so there is a good chance that bremsstrahlung from the beta particles is being detected in the HPGe. Due to the elevated background, it is difficult to verify that there are no weak additional lines. However, the lines that are observed were strong and from

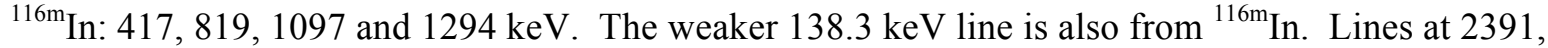
2529 , and $2808 \mathrm{keV}$ are sum peaks of the strong ${ }^{116 \mathrm{~m}} \mathrm{In}$. The thin indium foil was wrapped around the outside of the HPGe detector so there was a good probability of coincidences. There is also a $2112 \mathrm{keV}$ line from ${ }^{116 \mathrm{~m}} \mathrm{In}$, but it is difficult to resolve from an activated room background line from ${ }^{56} \mathrm{Mn}$ at 2113 $\mathrm{keV}$.

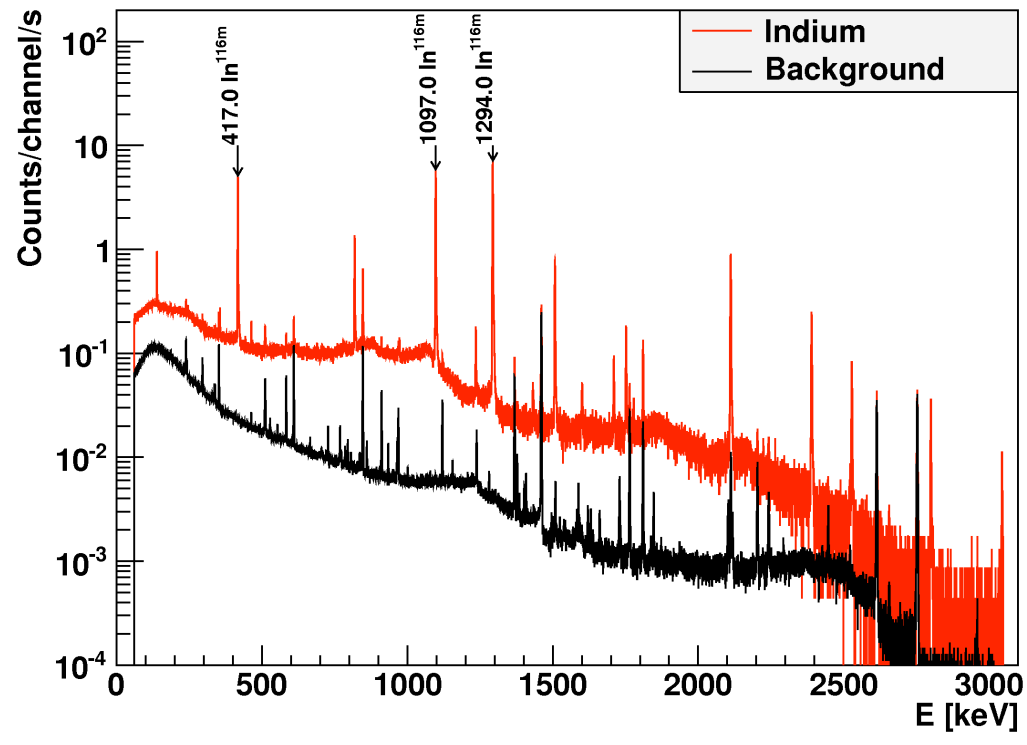

Figure 3: HPGe spectrum from indium foil. 


\subsection{Copper}

The copper spectrum, shown in Figure 4, is dominated by contributions from $\mathrm{Mn}^{56}$, likely from room background, as shown in Figure 2. The strongest gamma peak is the $1039 \mathrm{keV}$ peak from ${ }^{66} \mathrm{Cu}$. There is also a weak line at $1346 \mathrm{keV}$ from ${ }^{64} \mathrm{Cu}$. Most of the lines are from the background activation, but there are at least two, weak unidentified lines: 245 and $443 \mathrm{keV}$.

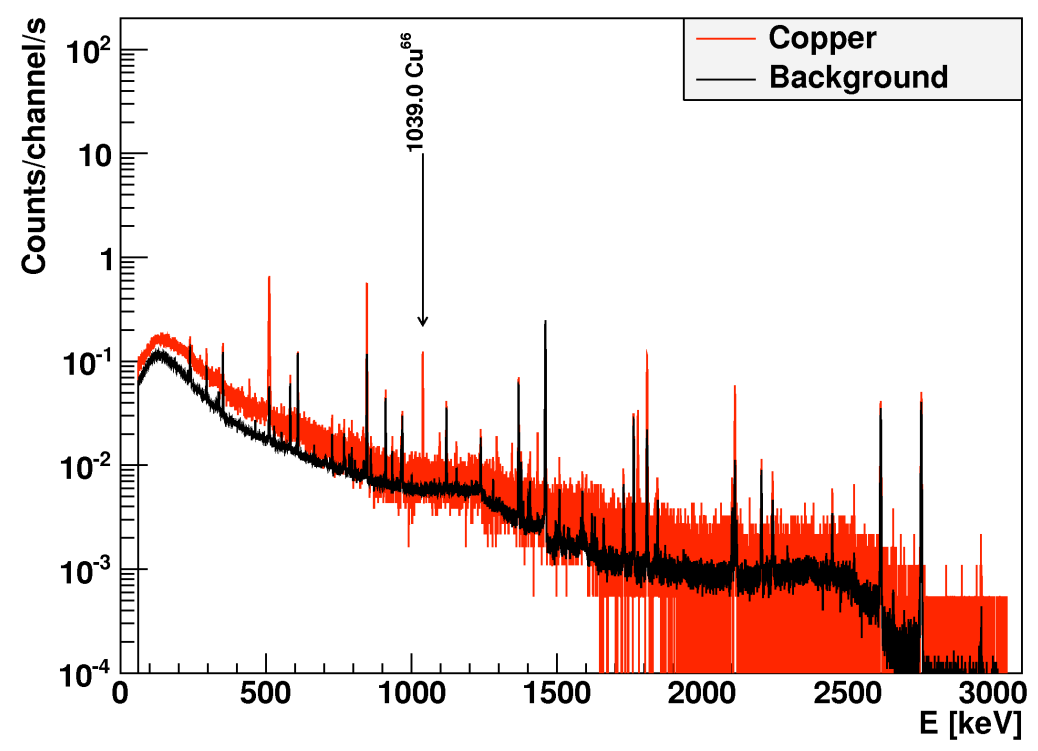

Figure 4: HPGe spectrum from copper. 


\subsection{Cadmium}

Figure 5 shows the HPGe spectrum for activated cadmium out to $3 \mathrm{MeV}$ while Figures 6 and 7 shows two selected energy regions. There are several naturally occurring isotopes of cadmium leading to several different excited nuclei. As a result, the gamma-ray spectrum is more complicated than for the other foils. Two energy regions were chosen where the known lines tended to cluster. Several lines from ${ }^{115} \mathrm{Cd}$ and ${ }^{117} \mathrm{Cd}$ are shown in Figures 6 and 7. There are additional lines which have not been identified. The cadmium also had an elevated counting rate of $312 \mathrm{cps}$ versus the $194 \mathrm{cps}$ of background. However, since the half-lives are in the several hours to days range, any residual ${ }^{115} \mathrm{Cd}$ and ${ }^{117} \mathrm{Cd}$ activity will decay away in a fairly short amount of time.

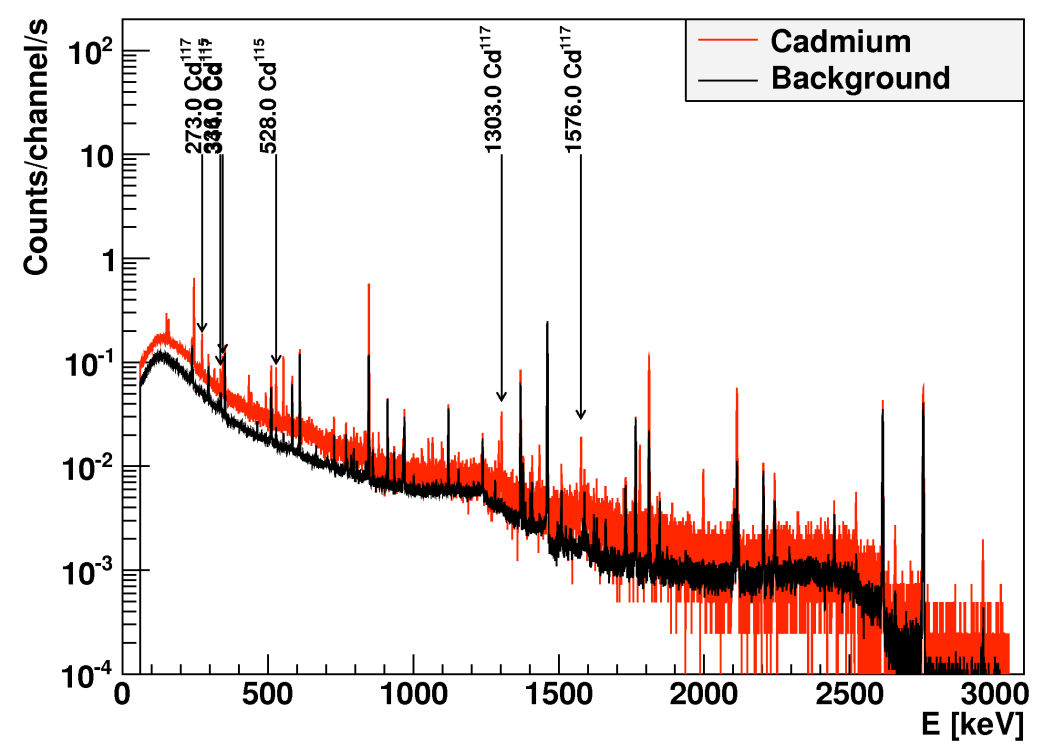

Figure 5: HPGe spectrum for cadmium. 


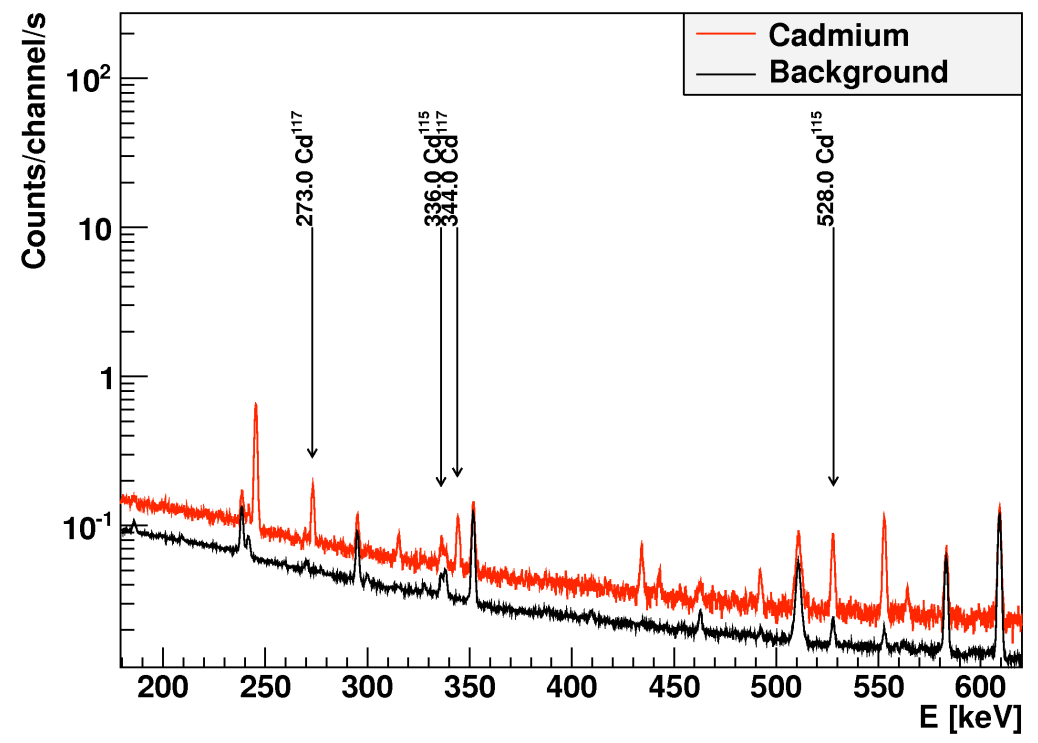

Figure 6: HPGe spectrum of cadmium in a lower energy region.

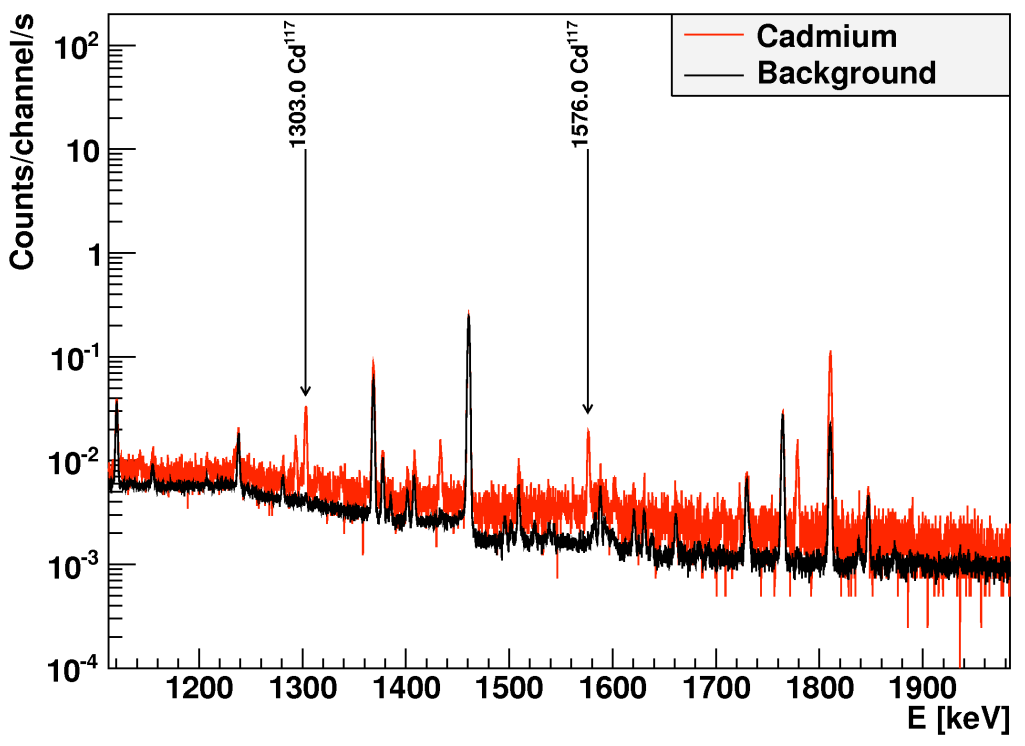

Figure 7: HPGe spectrum of cadmium in a higher energy region. 


\subsection{Cobalt}

Cobalt was one of the weaker sources due to the much longer half-life of the main product, ${ }^{60} \mathrm{Co}$. The two main lines from ${ }^{60} \mathrm{Co}(1173$ and $1332 \mathrm{keV})$ are just able to be seen in Figure 8.

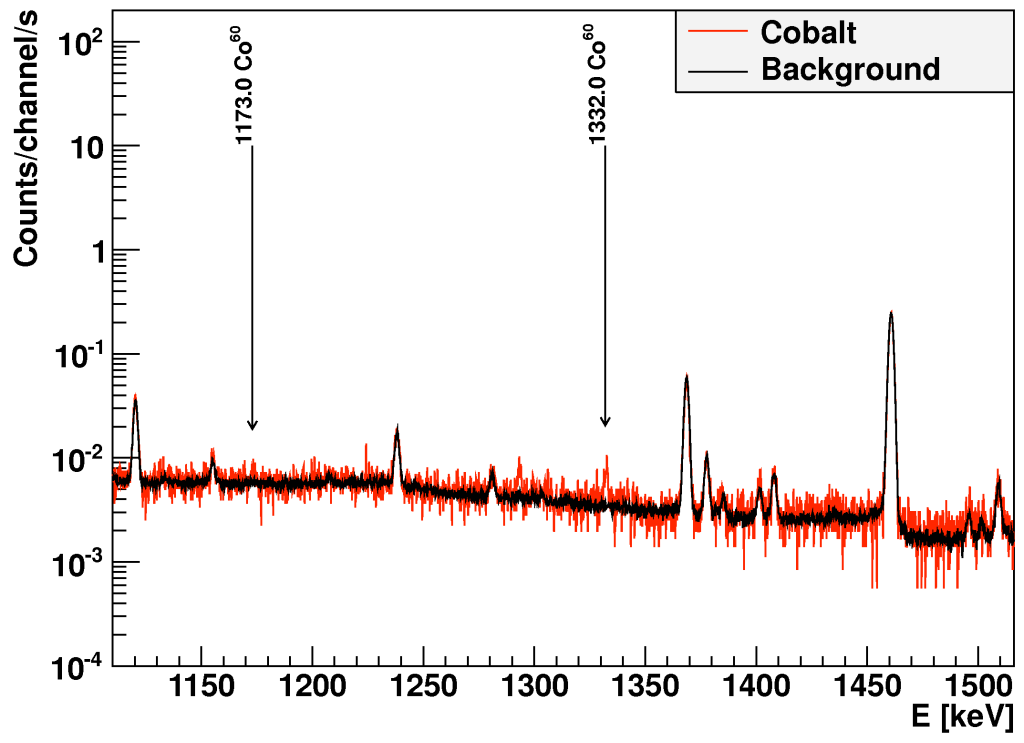

Figure 8: HPGe spectrum of activated cobalt. 


\subsection{Tantalum}

The results from tantalum are shown in Figure 9 and Figure 10. Even with the foil placed directly on the HPGe, the detector count rate started at $291 \mathrm{cps}$ and fell to $241 \mathrm{cps}$ after an hour (background rate was $194 \mathrm{cps}$ ). It is clear in Figure 9 that there is some elevation of the level of the continuum, but there are not any prominent peaks. Figure 10 shows the results in a small energy range so that the individual peaks can be more easily seen. The peaks are much clearer but not particularly strong. All of the peaks listed in Table 1 were observed except for $1147 \mathrm{keV}$, which may be present but is weak, and $1121 \mathrm{keV}$ which overlaps with a ${ }^{214} \mathrm{Bi}$ background line. The $1121 \mathrm{keV}$ counts are elevated above background.

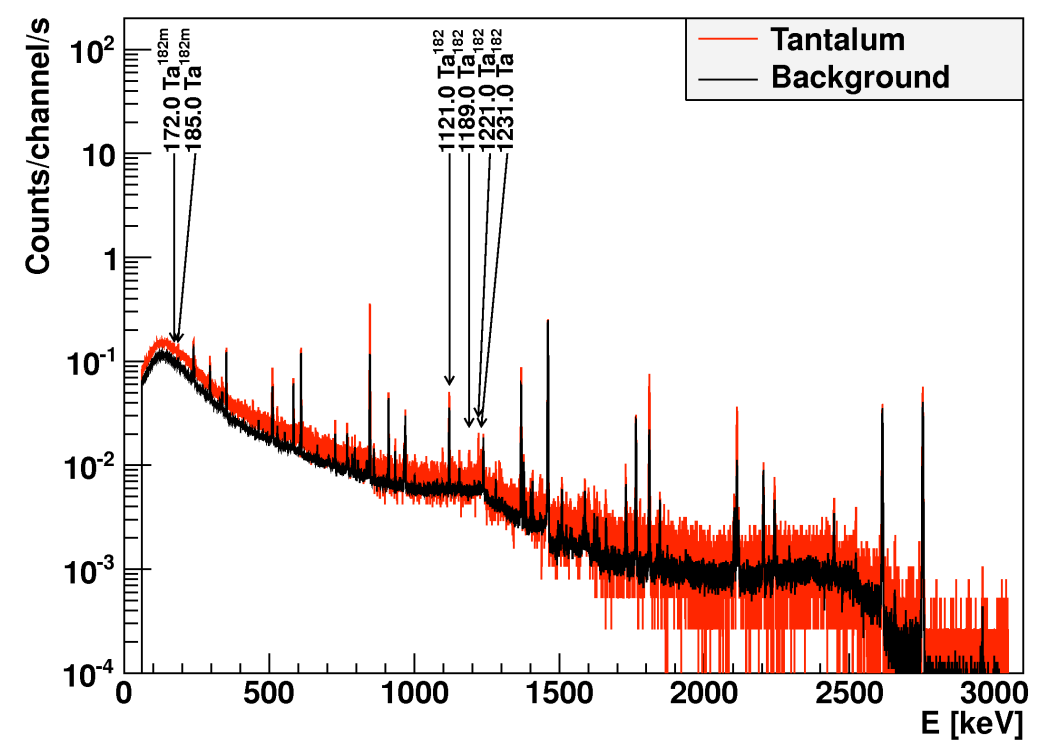

Figure 9: HPGe spectrum from activated tantalum. 


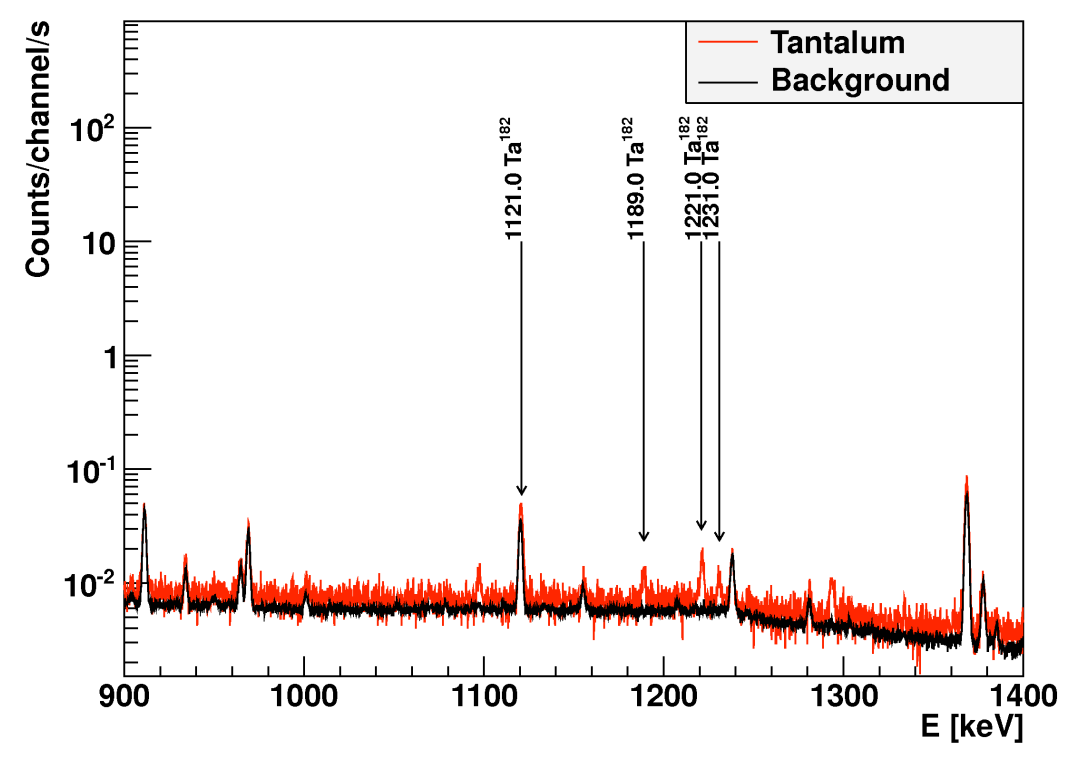

Figure 10: HPGe spectrum of tantalum in a small energy range.

\subsection{Conclusions}

The second set of activated samples presents minimal radiological risk. Only the indium foil registered a dose, $2.0 \mathrm{mR} / \mathrm{h}$ of betas at $1 \mathrm{inch}$. Activity was detected in each foil, but they are expected to rapidly decay with the relevant parent isotope half-lives on the scale of hours to days except for cobalt-60, which has a half-life of 5.3 years. Gamma rays from all the foils were observed using the HPGe detector. All of the expected gamma-rays were identified with only one exception in tantalum. The manganese background continues to make identification difficult when the activity is low.

Now that these additional foils have been found to present minimal radiological risk, future efforts will involve detecting the gamma rays emitted during the radiative neutron capture process. The metal foils were chosen because they have strong neutron absorption resonances in the neutron energy region of interest for the LSDS for this process. Through these measurements, we will be able to determine the time and energy correlation of the neutrons in the LSDS. 


\section{Appendix A: RPT Report}

Below are the initial survey reports covering the two days when the activations were completed.

Indium

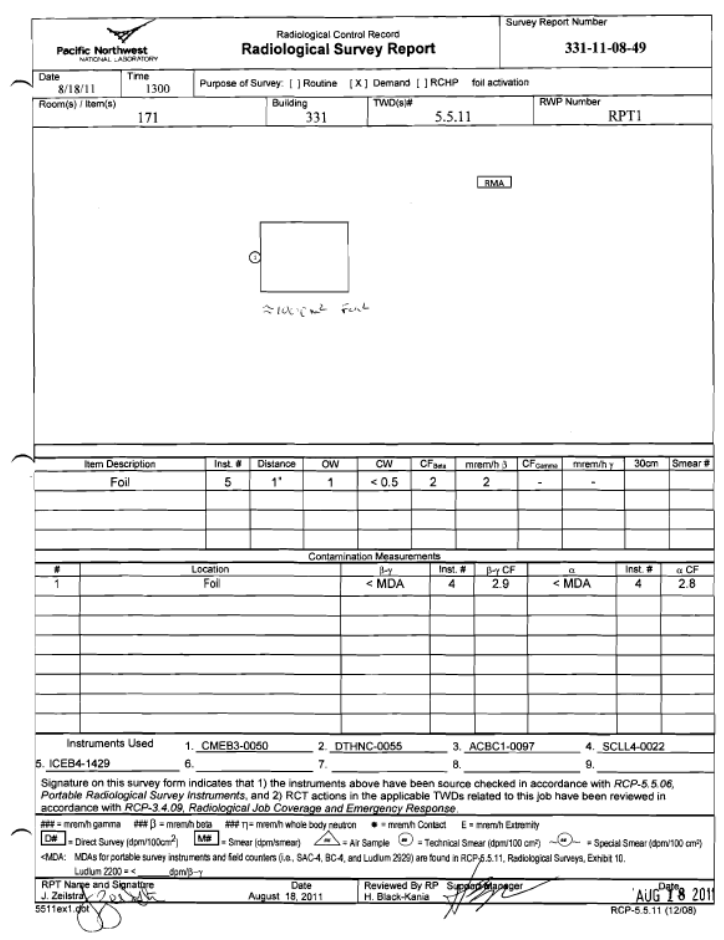

Copper

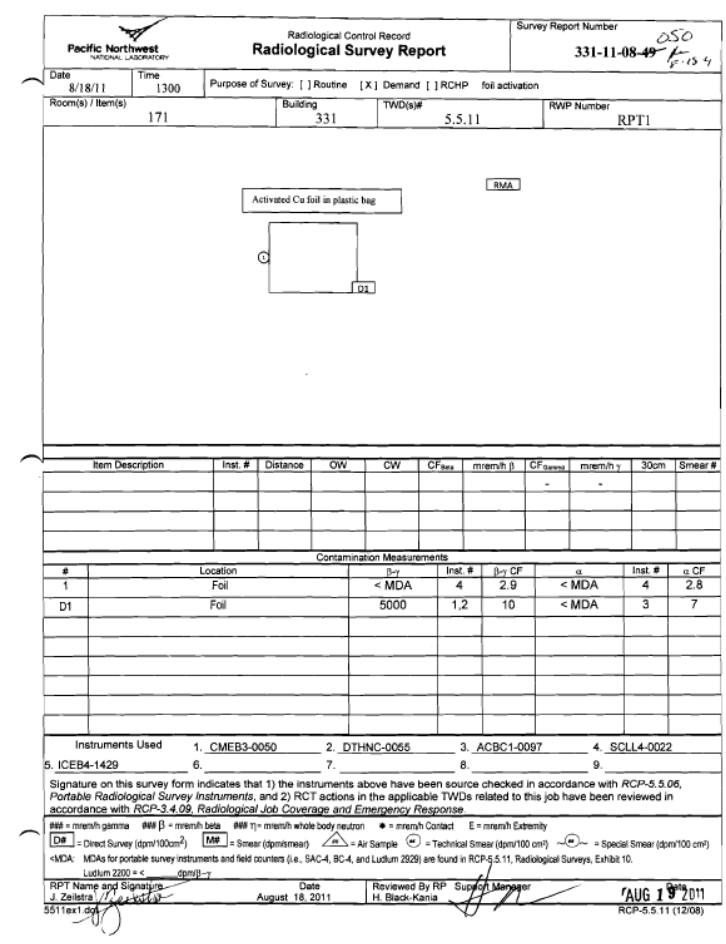


Cadmium

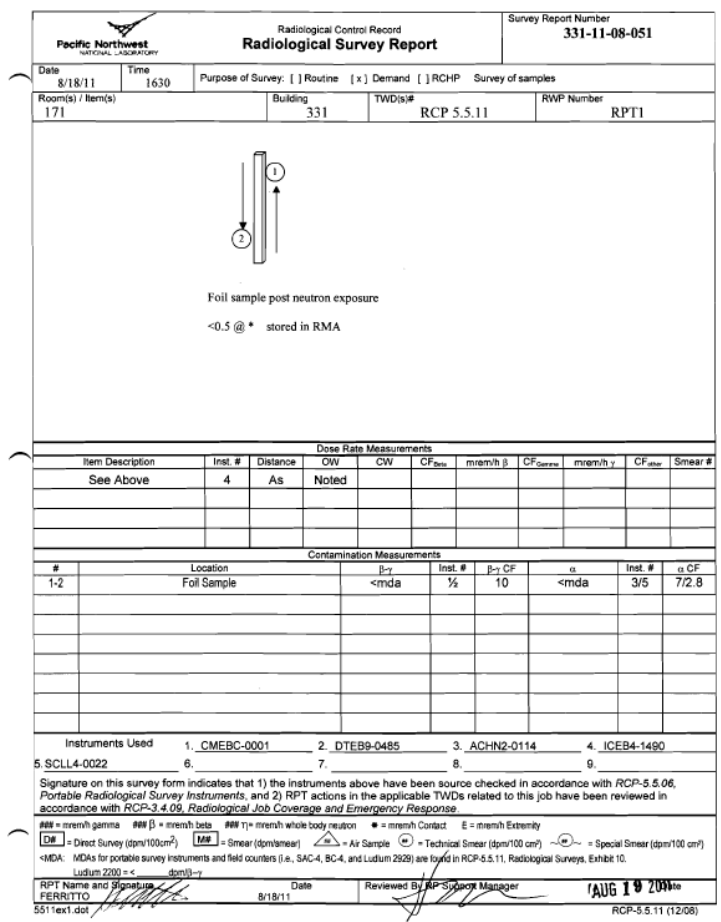

Cobalt and Tantalum

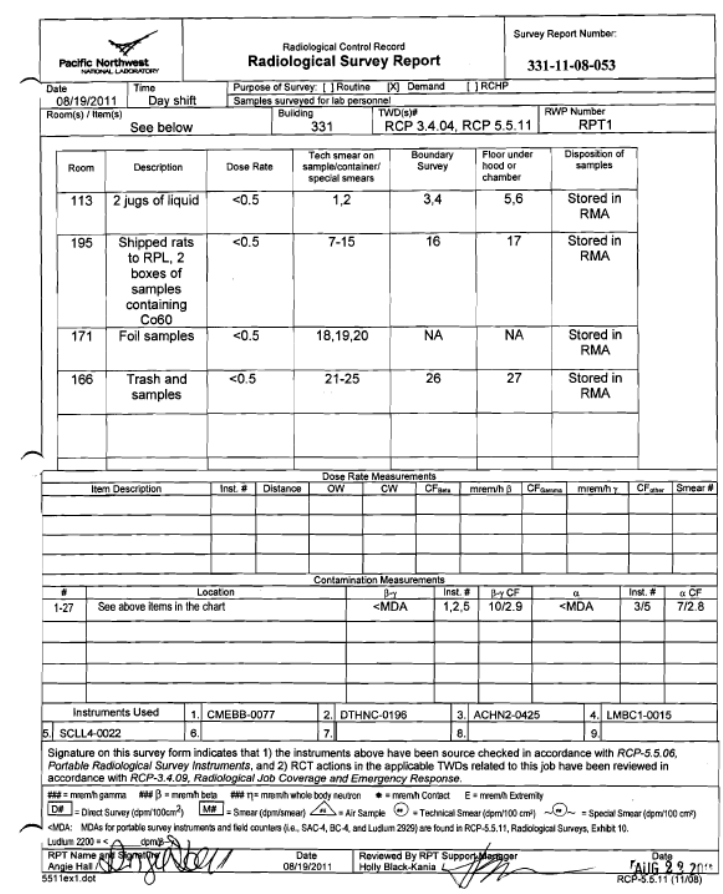




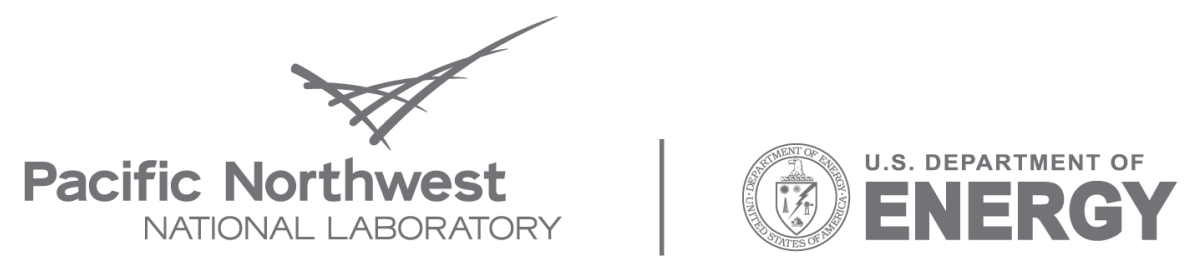

Proudly Operated by Battelle Since 1965

902 Battelle Boulevard

P.O. Box 999

Richland, WA 99352

1-888-375-PNNL (7665)

www.pnl.gov 